\title{
Sexual Assistance for People with Intellectual Disabilities: Proposal for a Service Delivery Model
}

\author{
Belén Gutiérrez-Bermejo ${ }^{1}$ (D) . Cristina Jenaro²
}

Accepted: 18 January 2022 / Published online: 4 February 2022

(c) The Author(s) 2022

\begin{abstract}
The figure of the sexual assistant is increasingly demanded as a right in the disabilities field. This figure requires debate, adaptation to the characteristics of countries and cultures, as well as to the characteristics of people with intellectual and developmental disabilities. This study presents the work carried out with representatives of Spanish organizations of people with intellectual disabilities to develop a proposal for the figure of support staff for sexual behavior. Together with a rights perspective, this proposal is aligned with the Supports paradigm to better meet the health and behavior needs of users. The figure is framed within the auto-erotic and therapeutic model of sexual assistance. This figure excludes characteristics of the erotic model that involves interaction or sexual exchange between the sexual assistant and the individual with a disability. Several advantages and disadvantages need to be carefully considered before implementing this support in a delivery service model. We argue that the proposed figure requires specific accreditation, training, and monitoring.
\end{abstract}

Keywords Sexual assistance $\cdot$ Intellectual disability $\cdot$ Model $\cdot$ Support needs $\cdot$ Spain

\section{Background}

For direct care professionals, heads of centers, and organizations working with people with intellectual disabilities, it is common to discuss issues related to sexuality. Traditionally, most of these topics have been addressed from a medical model [1]. This model emphasizes the role of the organic, heredity, pathology and deficits of people with disabilities without taking into account the context. This approach emphasizes the need for these people to be rehabilitated or treated by professionals who decide what is best for

Cristina Jenaro

crisje@usal.es

Belén Gutiérrez-Bermejo

mbgutierrez@psi.uned.es

1 Facultad de Psicología, PROTEDIS, Universidad Nacional de Educación a Distancia. Juan del Rosal, n 10, 28040 Madrid, Spain

2 Facultad de Psicología, PROTEDIS, INICO, Universidad de Salamanca. Avda. de La Merced, 109-131, 37005 Salamanca, Spain 
them and who typically offer their services in segregated environments [2]. In contrast, the emergence of a social model of disability considers that the disability is a result of ideology, public policy, cultural institutions and the physical environment $[1,3]$. This model considers disability to be a social construct and it is the demands within the context that impose barriers on people with functional diversity. Hence, this perspective stresses the importance of implementing actions to eliminate physical, architectural and attitudinal barriers that hinder equal opportunities [4]. The combination of the social model of disability with the rights-centered advocacy approach requires facing new challenges to fulfill the rights of this specific group. In the field of intellectual disabilities, there have been efforts to integrate the biomedical perspective with the psychoeducational, sociocultural, and justice perspectives into a holistic approach [5], in order to fully understand the challenges, needs and complexity of the intellectual disability. This holistic approach also sets the basis of our current proposal of a service delivery model of sexual assistance for people with intellectual disabilities.

The justice perspective included in this approach emphasizes that all individuals, including those with a diagnosis of intellectual disability, have the same human and legal rights as anyone else [5], and that one of these relates to sexuality [3]. As Mannino et al. [6] points out, in 1993 the General Assembly of the United Nations published the standard rules for the equalization of opportunities for persons with disabilities. These rules acknowledge the right of people with disability to live their sexuality [7]. Later, in 2006, the International Convention on the Rights of Persons with Disabilities [8] set the rights to home and family in article 3 [9], and sexual and reproductive rights in article 25. It should be noted, however, that neither the Convention nor the Standard Rules specifically refer to sexual assistance [10]. In March 2014, the World Association for Sexual Health (WAS) approved the declaration of sexual rights, [11] which are taken as reference in the field [6]. The WAS Sexual Rights are summarized in Table 1. Each of the rights that addresses a key issue that forms the premises and basis for the proposal of the sexual assistant figure that we present are highlighted in bold.

In their application to sexual rights, these and other national and international standards and laws require rethinking the services and supports provided to users for whom these rights have generally not been taken into account. This is also increasingly being demanded by different stakeholder groups This paper focuses on individuals that, as defined by the American Association on Intellectual and Developmental Disabilities [12], have a disability that originated before the age of 22 that imposes significant limitations in intellectual functioning and in adaptive behavior that covers many everyday social and practical skills. In many cases this population has experienced restrictions on the expression of their sexual interests, desires, and behaviors [13-16].

The debate in this field is related to three key concepts: sexuality, sexual health and sexual assistance. First, the WHO defines sexuality [17] as: "a central aspect of being human throughout life; it encompasses sex, gender identities and roles, sexual orientation, eroticism, pleasure, intimacy and reproduction. It is experienced and expressed in thoughts, fantasies, desires, beliefs, attitudes, values, behaviors, practices, roles and relationships. Sexuality is influenced by the interaction of biological, psychological, social, economic, political, cultural, legal, historical, religious and spiritual factors" (p.5).

As for Sexual Health, the WHO defines it as: "a state of physical, emotional, mental and social well-being in relation to sexuality. Sexual health requires a positive and respectful approach to sexuality and sexual relationships, as well as the possibility of having pleasurable and safe sexual experiences, free of coercion, discrimination and violence. For sexual 
Table 1 Human rights pertaining to sexuality

1. The right to equality and non-discrimination

2. The right to life, liberty, and security of the person. These include: sexual orientation, consensual sexual behavior and practices, gender identity and expression, and services related to sexual and reproductive health

3. The right to autonomy and bodily integrity. It includes free and informed consent prior to any sexuallyrelated testing, interventions, therapies, surgeries, or research

4. The right to be free from torture and cruel, inhuman, or degrading treatment or punishment, including harmful traditional practices; forced sterilization, contraception, or abortion

5. The right to be free from all forms of violence and coercion including rape, sexual abuse, sexual harassment, bullying, sexual exploitation and slavery, trafficking for purposes of sexual exploitation, virginity testing, and violence committed because of real or perceived sexual practices, sexual orientation, gender identity and expression, and bodily diversity

6. The right to privacy related to sexuality, sexual life, and choices regarding their own body and consensual sexual relations and practices without arbitrary interference and intrusion. This includes the right to control the disclosure of sexuality-related personal information to others

7. The right to the highest attainable standard of health, including sexual health; with the possibility of pleasurable, satisfying, and safe sexual experiences. This requires the availability, accessibility, acceptability of quality health services and access to the conditions that influence and determine health including sexual health

8. The right to enjoy the benefits of scientific progress and its applications in relation to sexuality and sexual health

9. The right to information related to sexuality, sexual health, and sexual rights

10. The right to education and the right to comprehensive sexuality education. It must be age appropriate, scientifically accurate, culturally competent, and grounded in human rights, gender equality, and a positive approach to sexuality and pleasure

11. The right to enter, form, and dissolve marriage and other similar types of relationships based on equality and full and free consent

12. The right to decide whether to have children, the number and spacing of children, and to have the information and the means to do so. It includes sexual and reproductive health services related to pregnancy, contraception, fertility, pregnancy termination, and adoption

13. The right to the freedom of thought, opinion, and expression through, for example, appearance, communication, and behavior, with due respect to the rights of others

Source: WAS, 2014

health to be attained and maintained, the sexual rights of all persons must be respected, protected and fulfilled" (p.5).

Sexual assistance is defined as [18]: "a sexual accompaniment service for people with disabilities that provides educational services about sexual practices and support services for sexual activity with the aim of meeting clients' sensual or sexual needs while bearing in mind the specific characteristics related to their disabilities" (p.20). Other authors further specify the sexual assistant as [19]: "any person who provides sexual assistance to physically and/or intellectually disabled people. By sexual assistance we mean one or more of these activities: sexual intercourse, oral sex, massage therapy including erotic massage, masturbatory acts, and discussion of sexuality, contraception, and the appropriate use of sex toys" (p. 2). Within this definition, very diverse possibilities exist with equally different limits. There are no service models for sexual assistance with individuals with intellectual disabilities that are generally accepted, agreed or utilized.

In Spain, Plena Inclusión, the organization that represents the associations on intellectual and developmental disabilities, published its position on the sexuality of this group 
[20] in 2017. In this document, it recognizes how little attention has traditionally been paid to this issue. Plena Inclusion also highlights the importance of providing support that allows these people to get to know their bodies, accept their gender identity, sexual orientation and express their sexuality in an appropriate and satisfactory way. Their position paper also states that this is a matter of rights that are internationally and nationally recognized. Likewise, their position holds that the approach to this issue must be preceded by ethical principles and must promote quality of life through the implementation of the necessary supports.

The report published in 2021 [21] on the implementation of this position paper on sexuality in the centers associated with Plena Inclusion reveals that the aspect that is least developed and, therefore, requires more work, relates to the provision of support, especially in relation to the enjoyment of masturbation. As indicated in this report, the data show that many people may be lacking this support and good professional accompaniment. This is also true for those with high support needs.

These results support the need to reflect on the subject of this article. Before presenting our proposal, we will review the models of sexual assistance and the state of the art worldwide.

Currently, there are three models of sexual assistance delivery [10]: (1) the Therapeutic model, (2) the Auto-erotic model, (3) the Erotic model. The Therapeutic Model is based on the idea that the person needs help or advice to solve difficulties in sexual matters. Its origins are in the 1970s in the United States, with the therapeutic techniques developed by Masters and Johnson for the treatment of sexual dysfunctions. This approach is rejected by the social disability movements because of its biomedical focus [22]. This model advocates the incorporation of a "substitute" or "surrogate" professional to advise, help or facilitate sexual behaviors [23]. At present, the International Professional Surrogates Association (IPSA) continues to be based on the methods of Masters and Johnson. In countries such as England, there are programs involving surrogacy [23].

The Autoerotic Model consists of instrumental erotic accompaniment [24]. According to this model, the sexual assistant supports the person with a disability in his or her sexual practices with others or with themselves but the sexual assistant does not have sexual relations with the person [25]. The Erotic Model consists of erotic accompaniment [24]. It is advocated by associations such as Sex Asistent, Tandem Team, and Touching Base [26]. According to this model, the sexual assistant can have full sex with the persons they assist. Sex assistants vary in terms of the specific training they receive, which may range from none to participation in a wide range of training courses [10, 18, 19, 26].

Sexual assistance was originally demanded from the field of physical disabilities by defenders of a social model of disability and by the independent living movement. Even within this context, it is recognized that this figure lacks a specific professional definition, as the theoretical models and corresponding professional practices vary between countries $[6,18,19,27]$. For example, in Germany, the sexual assistant has been regulated since 2017 under The Prostitute Protection Act. In Denmark, there are training programs that last longer than one year and social workers who complete the course are certified as sexual advisers [28, 29]. In the Netherlands, "sex care" is provided and subsidized in some instances for people with disabilities. Similarly, a growing number of private organizations worldwide such as Lovegiver in Italy (https://www.lovegiver.it/), APPAS (Association for the Promotion of Sexual Accompaniment) in France (https://www.appas-asso.fr/), and Touching Base (https://www.touchingbase.org/) in Australia, train people to sexually accompany people with disabilities. 
Worldwide, this figure assumes different titles such as "sexuality advisors", "sexual supervisors", "surrogate partnership", "sex surrogate", "facilitated sex", "intimate accompaniment", "erotic accompaniment", "sexual accompaniment", "sensual partner", and "intimate and erotic assistant". Different names have different nuances, depending on whether the figure acts solely as a facilitator or whether they are involved in sexual relations with the person with a disability [30]. In all cases, these workers accentuate their differences with sex work/prostitution in terms of the style of the relationship and the underlying motivation [27, 31-34].

In Spain, sexual assistance began in the physical disabilities field with the Independent Living Forum calling for this role in 2012 [35]. The public mobilization around this figure started in Barcelona in harmony with the appearance of other projects, such as the documentary "Yes, we fuck!" and following the founding of the organization Sex Asistent in 2012, by Silvina Peirano [10]. Subsequently, entities emerged such as Tandem Team and Sex Asistent in Catalonia and Aspasia in the Canary Islands. These entities emphasize a careful selection of users and assistants, for whom they establish contact so that users and assistants can later reach an agreement they freely decide upon [36]. Other organizations, such as the Instituto Sexológico Murciano, offer training for sexual assistants (http://www.formacion.isemu.es/) [24].

Among professionals and organizations representing individuals with intellectual disabilities, this topic is causing significant debate. Some organizations are in favor of implementing existing models for all types of conditions, including intellectual disabilities. Other organizations are reluctant to even implement therapeutic models. And regardless of the positions defended by the different organizations, they all agree on the need to reflect on this issue and to put forward a model proposal that is consistent with the rights of people with disabilities and with the human rights pertaining to sexuality (see Table 1).

When applying any of the above models to persons with intellectual and developmental disabilities, the figure of the sexual assistant requires further definition and roles clarification [37] as this figure was originally designed for people with physical disabilities who, by definition, do not have significant limitations in intellectual, conceptual, practical and social skills. The matter becomes even more complicated in the case of individuals with severe intellectual disabilities who may not be able to communicate their needs [38].

From a holistic approach, the intellectual disability is acknowleged to be characterized by significant limitations both in intellectual functioning and in adaptive behavior as expressed in conceptual, social, and practical adaptive skills. To mitigate these limitations, a comprehensive set of interventions and supports are required and, as Schalock et al., state [5], are viewed broadly to include biomedical interventions, educational strategies, public attitudes and perceptions, right affirmation, and judicial decisions. The elements of a system of supports may include technology, prosthetics, teaching new skills, environmental accommodation, and professional services, among others. As summarized in Table 2, a multidimensional response to dfferent sexual needs and demands requires actions aimed at the individual, as well as his/her environment. Such interventions and supports need to be relevant, appropriate, timely, consistent, person-centered, respectful, evidence-based, and effective [5].

Support needs are one of the defining characteristics of intellectual disabilities. These needs also extend to other areas of daily life such as sexuality. Those with intellectual disabilities have less access to normalized environments where they can develop their sexuality in a satisfactory way. They have less or biased knowledge about sexuality and they also present a deficit in skills to provide themselves with pleasure or to provide pleasure to 
Table 2 Components, indicators, and examples of needs and/or demand concerning sexuality from a holistic approach

\begin{tabular}{lll}
\hline $\begin{array}{l}\text { Theoretical Component } \\
\text { of the holistic model }\end{array}$ & Indicators & $\begin{array}{l}\text { Examples of needs/ } \\
\text { demands concerning } \\
\text { sexuality }\end{array}$ \\
\hline Biomedical & Genetic/neurological/physiological impairment & $\begin{array}{c}\text { Preventing self-injuries } \\
\text { with masturbatory }\end{array}$ \\
& & practices \\
& & Prosthetics \\
Educational & Significant limitations in intellectual functioning and & Information \\
Public attitudes and & conceptual, social, and/or practical skills & Skills \\
perceptions & Systems of supports & Having a partner \\
Right affirmation & Environmental accommodation & Expressing sexual interest \\
Judicial decisions & Consent & Privacy in sexual matters \\
& & Marriage \\
\end{tabular}

others $[39,40]$. In addition, those who present high support needs may also have functional difficulties such as motor difficulties to respond to their sexual arousal satisfactorily.

Adaptation to the characteristics of countries and organizational cultures is also necessary. All these issues have been taken into account in the process that we followed to develop the proposed model.

In light of this background, the goals of this study were: (1) to disseminate information on the figure of sexual assistance for intellectual disability; (2) to promote discussion in centers and services for people with intellectual disabilities on a holistic sexual assistance proposal in accordance with the mission and values of Plena Inclusión, and (3) to offer a consensual proposal for advancing the provision of support and professional accompaniment for the enjoyment of eroticism and autoeroticism.

\section{Methods}

\section{Study Setting and Participants}

The study was conducted in the Basque country and was supported by FEVAS (Basque Federation of Associations on Intellectual and Developmental Disabilities, https://fevas. org/fevaspi). This organization brings together all the entities that work with people with intellectual and developmental disabilities in the Basque Country, one of the regions of Spain. These Basque country entities support a total of 11,985 people with intellectual or developmental disabilities, 12,172 families, 2,450 professionals and 1,360 volunteers. FEVAS is part of the national network of entities concerning people with intellectual and developmental disabilities called Plena Inclusion.

Professionals from PROTEDIS and FEVAS set up an ethics group to discuss this issue with representatives of the six organizations involved. Those organizations represent the three regions of the Basque country: Araba (Apdema, Fundación Tutelar Usoa), Bizkaia (Apnabi, Aspace Bizkaia), and Gipuzkoa (Gautena, Uliazpi), The group included organizations representing different conditions such as intellectual disability, autism spectrum disorder, and cerebral palsy. 
Each organization had two professionals who took turns attending the meetings, collecting feedback from their center, and disseminating the information from the face-to-face sessions. The study was approved by FEVAS and all participants involved in the discussion process voluntarily agreed to participate. Confidentiality and anonymity in the process of deliberation and sharing of experiences were guaranteed.

\section{Procedure}

The group met once a quarter in 2019. At each session, objectives to be achieved, topics to be discussed, tasks to be carried out in the respective centers, and information commitments to be brought back to the working group were set.

In the first session, the working group discussed how to best respect the rights of individuals with intellectual disabilities. The support needs framework to meet the needs of these individuals was also emphasized. Here, there is a growing focus in program planning and resource allocation based on the intensity of an individual's support needs, instead of relying solely on measures of personal competence, such as adaptive behavior [43]. According to this model, a person's intensity of support needs is the function of interactions among multiple variables associated with an individual (intellectual functioning, adaptive functioning, physical and mental health, problem behavior, level of activity), and their environmental demands [44]. The Supports Intensity Scale, SIS [43, 45] a commonly used measure by Plena Inclusión services and centers, was utilized as a framework to discuss the profile and intensity of support needs of their users, as well as the best approach to deliver services to promote independence and community integration [45-47]. The SIS is divided into three sections: The first section, The Supports Needs Scale, includes six domains: Home Living, Community Living, Life-long Learning, Employment, Health and Safety, and Social activities. The second section relates to Supplemental Protection and Advocacy domains. The third section, Exceptional Medical and Behavioral Support Needs, includes medical conditions and problem behaviors commonly associated with intellectual disabilities [45]. Within this framework, we identified potential areas of support pertaining to sexuality, sexual health, and sexual rights (see Table 3).

Next, the group discussed the problems concerning sexuality faced by the users of their respective centers from a psychoeducational, sociocultural, and rights perspective. There was agreement that, in contrast to people with physical disabilities, the vast majority of people with intellectual disabilities do not have medical support needs related to mobility or the like, that could limit their opportunities to engage in sexual behavior. On the other hand, the group agreed that support needs in several life domains are quite common for this population. For example, they may lack information and training on sexuality issues $[48,49]$. Providing adapted and accessible information, training, and education relates to the rights set out in WR 9 (information) and WR 10 (education). The training must include areas such as those found in the Protection and Advocacy section, which are consistent with rights, such as non-violence (WR 5) and privacy (WR 6) (See Table 1). On the other hand, supports for advocacy is key, as several studies [13,50-52] reveal that context may place barriers to the rights recognized and embodied in Table 1, such as freedom (WR 2), autonomy (WR 3), the right to have a partner (WR 11), to parenthood (WR 12) and to express the sexuality (WR 13).

The group went on to discuss the figure of the sexual assistant (roles, differences between this figure and that of a sex worker, regulation, etc.). Finally, scientific articles on the use of this figure in the disabled population and the different existing models were 


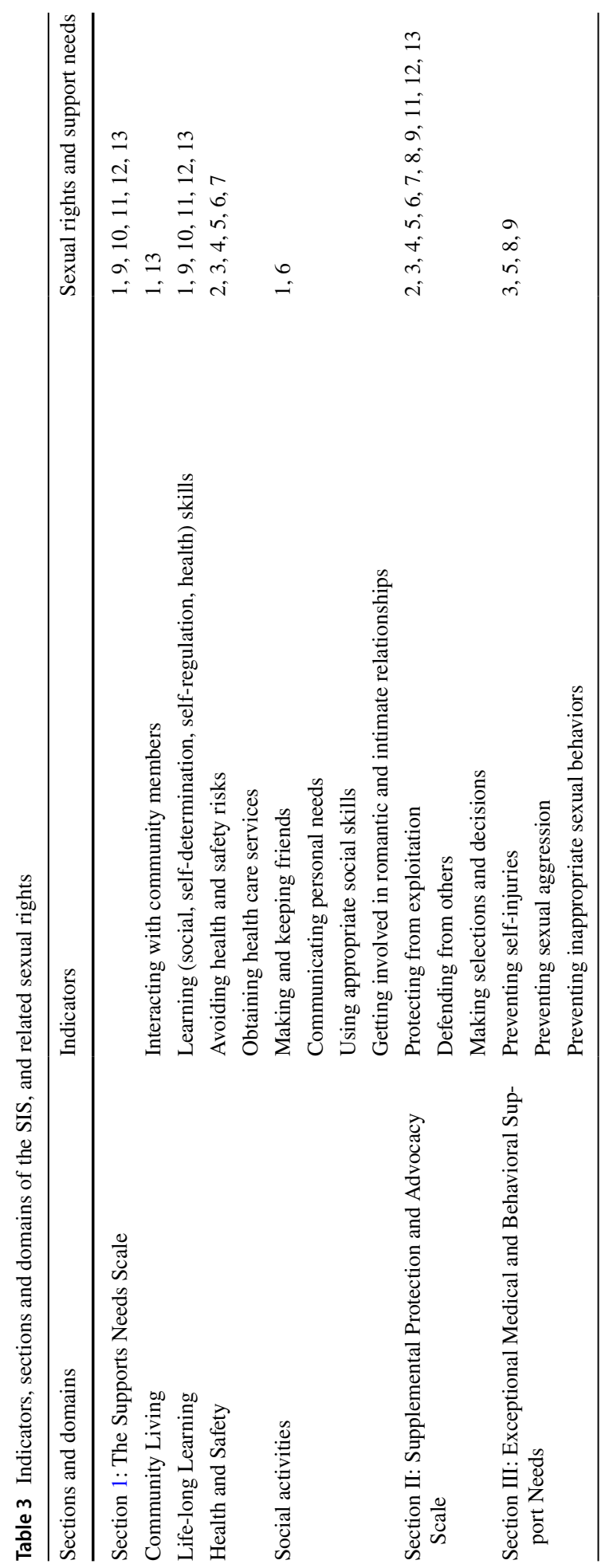


distributed. The group agreed to read and reflect on the documents provided for the next session, as well as to collect the impressions of their stakeholders on this figure.

In the second session, the different models of sexual assistance were presented and discussed. The representatives of each center analyzed the viability of the implementation of each model and the ethical, legal and technical aspects involved. A holistic approach requires that, together with a rights perspective, the notions of respectful, responsible, and consensual sexual behaviors $[39,41]$ be highlighted, as well as the need to promote health and security and prevent any type of abuse $[39,42]$. A consensus was reached on the professional figure most in line with the mission and vision of the centers and with the institutional position on sexuality expressed by Plena Inclusión [20]. The participants also agreed to disseminate the proposal and to consult on the feasibility to draft a consensus document.

The third session focused on the drafting of the different sections of the consensus document. This involved establishing a title for the position and a definition for this professional figure, as well as determining the sections and contents to be included in the document. The group agreed to revise the wording and contents and to include any other elements contributed by their centers.

The fourth session involved making decisions on the final wording, the inclusion or exclusion of contents, and the proposal of a dissemination plan in the different centers. As a preliminary step, it was agreed to disseminate the proposal on the PROTEDIS webpage and in scientific articles as a way to reach other organizations associated with Plena Inclusión, and to encourage scientific debate on the subject, both nationally and internationally.

\section{Results}

\section{Proposal for a Sexual Behavior "Support Person" for Users with Intellectual Disabilities}

In keeping with a holistic framework, the figure proposed is not intended to replace the training requirements and responsibilities of a center and its professionals. This figure is proposed as part of external services that the organization must be aware of in order to refer users to accredited services. An educational-therapeutic model, as opposed to an erotic model, is proposed for the following reasons:

- Services for persons with intellectual and developmental disabilities should be as normalized and inclusive as possible.

- Accessing sexual services regardless the setting (training, work or residential settings) conveys the idea that sexual behavior is appropriate whenever sexual arousal is experienced, which nullifies any educational action in this regard.

- Arguing that adults with intellectual disabilities have fewer opportunities to engage in sexual behavior and satisfy their impulses is, in many cases, incorrect and prejudiced [53].

- Organizations for persons with intellectual and developmental disabilities have professionals with accredited training, such as psychologists, sexuality specialists, etc., who are responsible for dealing with support needs concerning sexual education, sexual health, and sexual rights [54-56]. Clear limits between the professional and the person 
with intellectual and developmental disabilities should prevent the confusion of roles, and dysfunctional emotional involvement.

- This model is aimed at those people who wish to have sexual behaviors with themselves or others but do not know how to engage in it effectively. It also targets those who may require additional support because of a substantial medical/physical limitation. Here, a personal assistant may provide this support in a therapeutic and desexualized context as part of a health promoting activity.

- There are people with intellectual disabilities who may choose to use the services of sex workers/prostitution services. If this is the case, a series of premises are raised: (1) As a personal decision it should be financed with personal funds; (2) the use of this figure should be made outside of the scope of an institution's responsibility; (3) Persons with intellectual disabilities accessing sexual workers should be encouraged to be aware of the limits of this activity and to comply with criteria of safety, health, and respect, among others [39].

The figure proposed should be aimed at responding to specific and extraordinary needs that cannot be met with the current or available human resources in an organization. Three elements stand out in this definition. First, it should not be normative. Second, ordinary support needs, even those of high intensity, must be met with the existing professional resources. Third, the lack of human resources to respond to these needs (for example, if the need is identified in a work environment, or if the center does not allow certain practices) must be met with external support. Some examples where this professional service might be appropriate are the following:

1. In a residence a young man with intellectual disability and cerebral palsy performs masturbatory behaviors against the bars of the bed that result in physical injuries to his genitals. This behavior may reflect support needs to prevent self-injuries (Table 2).

2. At home, a young adult with autism shows high sexual arousal and autoerotic behaviors that he does not perform effectively, prompting his mother to masturbate him. This behavior may reflect support needs to prevent sexual aggression and inappropriate sexual behaviors, as well as the need to increase his life-long skills.

3. At home, a young woman injures her genitals by using objects to stimulate herself. In this case, supports to avoid health risks are advisable.

4. In a supervised apartment, a couple requests support to have intercourse because they hurt themselves when they trying. In response to those needs, life-long supports may create a difference.

5. A person with intellectual disability living in a supervised apartment asks for support in using sex work/prostitution services, as he is very shy and does not feel capable to initiate a relationship. In this regard, supports for social activities seem useful.

\section{How to use the Figure of the Sexual Behavior Support Person}

Given the variety of situations and settings in which these demands may appear, the first step is to collect information about the behavior and support needs. Accredited instruments, such as the SIS, as demonstrated in Table 2, may help identify the frequency, intensity, and duration of the support needs. Secondly, the center and organization receiving this information must rely on professionals (psychologist, social worker, physician, occupational 
therapist, educators), with competences for dealing with the issue. We highlight the term "competencies for" since having professional qualification does not imply having legal or ethical authority to meet that request. Whenever possible, the action should be carried out in the center. Otherwise, referral to an external professional should be made. This is the place of the support person for sexuality.

Referral does not imply neglect. Therefore, communication between professionals must be ensured, allowing for the sharing of evaluation data and follow-up. Both tasks can be more or less extensive and detailed, depending on the characteristics of the person with intellectual and developmental disabilities and the behavior under assistance. It is also important to note that referral does not necessarily mean "out of center", as the behavior must be addressed, if appropriate, where the behavior takes place. The intervention should take place in the most natural environment as possible (as long as it is the right one), which will facilitate its maintenance after support is withdrawn.

As is widely recognized, regardless of the severity of the intellectual disability, with the necessary supports, behavior will generally improve [12]. Therefore, people in our previous examples may eventually learn to perform autoerotic behavior correctly, or to have full and satisfying sexual behavior with their partner, or to use prostitution services in a safe and respectful way. Consequently, the figure of the support person will no longer be necessary.

\section{Required Training of the Sexual Assistant Figure}

The ethic group agreed that basic training in social and health activities, acquired through official institutions, is required. This training is based on the figure of personal assistant, currently regulated in Spain by the Law 39/2006 of 14 December. This professional, not to be confused with sexual assistant, performs or collaborates with the dependent persons' everyday tasks, with the aim of encouraging their independent living as well as promoting and reinforcing their personal autonomy. Although the specific training of these professionals is pending regulatory recognition, at present, all professionals who work as home help aides, personal assistants, or who can prove at least 3 years of experience, with a minimum of 2,000 h worked, or who have a minimum of $300 \mathrm{~h}$ of training related to this subject, will have the legal recognition of this professional qualification as personal assistant.

To this training and experience we propose that they must also receive an additional 40-h of training (see Table 4), endorsed by organizations such as PROTEDIS (http://blogs. uned.es/protedis/) or the like. This training must include general information on disability from a holistic approach, specific training on sexuality matters, as well as information on ethical issues concerning supporting sexuality in intellectual disabilities.

\section{Discussion}

There is a need for further training and education of professionals, close persons, and caregivers in order to provide qualified support to individuals with intellectual disabilities regarding sexuality [57]. The present proposal assumes a holistic approach and is the result of discussion and debate with representative entities of persons with intellectual disabilities with a wide range of support needs. This proposal develops the figure of support personnel in sexual behavior. This figure must have basic professional training, to which about $40 \mathrm{~h} \mathrm{is}$ added. This professional shares characteristics of the therapeutic model and the autoerotic model. Interventions should be carried out, whenever possible, in the natural context where 
Table 4 Proposed training for support personnel in sexual behavior

Block 1. Training by disability specialists $(15 \mathrm{~h})$

Current conception of disability and characteristics

Current conception of adaptive behavior

Current conception of the areas and needs for support

Current concept of quality of life in people with intellectual and developmental disabilities

Rights of persons with disabilities

Attitudes towards people with disabilities

Factors influencing the sexual development of persons with intellectual and developmental disabilities

Sexual consent in persons with intellectual and developmental disabilities

Block 2. Training by specialists in sexuality $(20 \mathrm{~h})$

Sexuality Fundamentals

Attitudes towards Human Sexual Behavior

Distinctions between adaptive erotic behaviors and others that could generate distress

Good relations and consent in erotic relationships

Learning to pleasure yourself and the different forms of erotic expression

Learning to give pleasure with the different forms of expression of eroticism (including masturbation)

Erotic toys and supports and their use by persons with disabilities

The role of sexual assistance in the context of different demands

Block 3. Training by specialists in ethics $(5 \mathrm{~h})$

Ethics in sexual assistance

Case studies

the behavior takes place, as long as this context is appropriate to initiate the behavior. Given the diversity of organizations and the types of settings in which these behaviors may occur, support staff may be part of the institution, although in most cases this will be an external figure offering supports of varying frequency, intensity and duration. The support is intended to be temporary, to be phased out as problems are resolved or demand ceases. The centers must ensure the quality of the services provided, which requires evaluation and monitoring of the process and the results.

Finally, there are several advantages and disadvantages that need to be carefully considered before implementing this support in a service delivery model. Among the positive aspects or advantages, this figure addresses a right recognized in the Convention for persons with disabilities. It also promotes life-long learning and is in accordance with the supports paradigm, so it can help meet behavioral support needs related to sexual matters. It allows the centers to be responsive to a quite generalized issue. In addition, it provides role differentiation (family, trainers, technicians, caregivers, personal assistant and sex worker), an important aspect given that the family sometimes assumes the figure of a sexual assistant, something which is not advisable from the point of view of roles ambiguity. Additional advantages, from a right perspective, relate to the fact that this role makes it possible to raise awareness, concerning normalization; it can prevent abuse and the secrecy surrounding these issues. Finally, it can be used as a "rescue resource" or "third level", with the intention of being "temporary support".

Concerning negative aspects and disadvantages, limits must be made clear or it can lead to boundary confusion. For example, it can lead to frustration by raising expectations or "opening up" the need to "go beyond". Second, it is important to monitor the process, as the person with intellectual disabilities may become emotionally attached to the 
professional. Next, for organizations supporting this professional figure, planning, investment and financial management are required, as this professional figure does not exist in many regions. Likewise, planning is also required concerning practical matters. For example, privacy must be guaranteed, adequate spaces must be provided, and spaces allocated for other uses must be respected so as not to lead to the confusion of tasks and activities. It is also important to work with the family first, as this figure can generate opposition. Even the term "sexual assistant" may need to be renamed to make clear what is meant by this figure. Also, in order to guarantee all these issues, the training of the sexual assistants should be compulsory and accredited. Finally, process monitoring is required to avoid the risks of any kind of abuse (sexual or otherwise).

\section{Conclusions}

The needs, in relation to information and sexual training, sexual health, and sexual rights of people with intellectual disabilities must be assessed and responded to appropriately from a holistic approach. While most of the needs can and should be addressed from the centers and services themselves, specific needs in relation to sexuality may require external support. The figure of the sexual assistant for this population should be based on a therapeutic and autoerotic model. In addition, this figure requires specific accreditation, training, and monitoring. This proposal leaves out alternatives such as the erotic model that is defended by other authors and by some groups of people with disabilities.

Acknowledgements The authors wish to thank FEVAS Plena inclusión Euskadi for the enriching the debates and their involvement in this proposal

Author contributions B.G-B designed the study and obtained the collaboration with FEVAS, with contributions from C.J. Both authors carried out the discussion sessions, and data gathering and feedback with the organizations. Likewise, both authors analyzed the process and outcomes, and drafted the manuscript. Finally, B.G-B and C.J. read and approved drafts of the manuscript, including the final version.

Funding Open Access funding provided thanks to the CRUE-CSIC agreement with Springer Nature. No funding was received for the current study.

Data availability This is a summary of the reflection process and is a consensus document. Additional material can be requested at PROTEDIS (Protection service to people with disabilities): http://blogs.uned.es/ protedis

\section{Declarations}

Conflict of interest The authors declare that they have no competing interests.

Open Access This article is licensed under a Creative Commons Attribution 4.0 International License, which permits use, sharing, adaptation, distribution and reproduction in any medium or format, as long as you give appropriate credit to the original author(s) and the source, provide a link to the Creative Commons licence, and indicate if changes were made. The images or other third party material in this article are included in the article's Creative Commons licence, unless indicated otherwise in a credit line to the material. If material is not included in the article's Creative Commons licence and your intended use is not permitted by statutory regulation or exceeds the permitted use, you will need to obtain permission directly from the copyright holder. To view a copy of this licence, visit http://creativecommons.org/licenses/by/4.0/. 


\section{References}

1. Santos, A.C., Santos, A.L.: Yes, we fuck! Challenging the misfit sexual body through disabled women's narratives. Sexualities 21(3), 303-318 (2018). https://doi.org/10.1177/1363460716688680

2. Devlieger, J.P., Rusch, F., Pfeiffer, D.: Rethinking disability: The emergence of new definition concepts, and communities. Garant, Antwerp, Belgium (2003)

3. Bahner, J.: Legal rights or simply wishes? The struggle for sexual recognition of people with physical disabilities using personal assistance in Sweden. Sex Disabil. 30(3), 337-356 (2012). https://doi.org/ 10.1007/s11195-012-9268-2

4. Purtell, R.: Music and the social model of disability. In: Williams, J. (ed.) Music and the social model: An occupational therapist's approach to music with people labelled as having learning disabilities, pp. 26-32. Jessica Kingsley, London (2013)

5. Schalock, R.L., Luckasson, R., Tasse, M.J., Verdugo, M.Á.: A holistic theoretical approach to intellectual disability: going beyond the four current perspectives. Intellect. Dev. Disabil. 56(2), 79-89 (2018). https://doi.org/10.1352/1934-9556-56.2.79

6. Mannino, G., Giunta, S., Fiura, G.: Psychodynamics of the sexual assistance for individuals with disability. Sex Disabil. 35(4), 495-506 (2017). https://doi.org/10.1007/s11195-017-9491-y

7. United Nations: Standard Rules on the Equalization of Opportunities for Persons with Disabilities. United Nations, New York (1994)

8. United Nations: Convention on the Rights of Persons with Disabilities (CRPD). United Nations, New YOrk (2006)

9. Navas Macho, P., Gómez Sánchez, L.E., Verdugo Alonso, M.A., Schalock, R.: Derechos de las personas con discapacidad intelectual: Implicaciones de la Convención de Naciones Unidas. Siglo Cero 43(3), 7-28 (2012)

10. García-Santesmases, A., de Branco Castro, C.: Fantasmes i fantasies: controvèrsies sobre l'assistència sexual per a persones amb diversitat funcional. Pedagogia i Treball Soc. 5(1), 3 (2016). https://doi.org/10.33115/udg_bib/pts.v5i1.22161

11. World Association for Sexual Health WAS. Declaration of sexual rights. the World Association for Sexual Health, Minneapolis, USA (2014).

12. Schalock, R.L., Luckasson, R., Tassé, M.J.: Intellectual Disability: Definition, Diagnosis, Classification, and Systems of Supports (12th Ed). AAIDD, DC, Washington, DC (2021).

13. Black, R.S., Kammes, R.: Restrictions, power, companionship, and intimacy: a metasynthesis of people with intellectual disability speaking about sex and relationships. Intellect. Dev. Disabil. 57(3), 212-233 (2019). https://doi.org/10.1352/1934-9556-57.3.212

14. Frawley, P., Wilson, N.J.: Young people with intellectual disability talking about sexuality education and information. Sex Disabil. 34(4), 469-484 (2016). https://doi.org/10.1007/s11195-016-9460-x

15. McClelland, A., Flicker, S., Nepveux, D., Nixon, S., Vo, T., Wilson, C., Marshall, Z., Travers, R., Proudfoot, D.: Seeking safer sexual spaces: queer and trans young people labeled with intellectual disabilities and the paradoxical risks of restriction. J. Homosex. 59(6), 808-819 (2012). https://doi. org/10.1080/00918369.2012.694760

16. Yau, M.K., Ng, G.S., Lau, D.Y., Chan, K.S., Chan, J.S.: Exploring sexuality and sexual concerns of adult persons with intellectual disability in a cultural context. B. J. Dev. Dis. 55(109), 97-108 (2009). https://doi.org/10.1179/096979509799103089

17. World Health Organization: Sexual health, human rights and the law. WHO, Geneva (2015)

18. Morales, E., Quattrini, F., Auger, C., Gauthier, V.: What sexual assistants want and need: creating a toolkit and new solutions to help them better perform their work with individuals with disabilities. Sex Disabil. 38(1), 19-29 (2020). https://doi.org/10.1007/s11195-019-09614-2

19. Limoncin, E., Galli, D., Ciocca, G., Gravina, G.L., Carosa, E., Mollaioli, D., Lenzi, A., Jannini, E.A.: The psychosexual profile of sexual assistants: an internet-based explorative study. PLoS One 9(2), e98413 (2014). https://doi.org/10.1371/journal.pone.0098413

20. Plena Inclusión: Posicionamiento institucional sobre sexualidad delas personas con discapacidad intelectual o deldesarrollo. https://www.plenainclusion.org/informate/actualidad/noticias/2017/ posicionamiento-institucional-sobre-sexualidad-de-las-personas (2017). Accessed November, 2017

21. Inclusión, P.: Evaluación de la implantación del Posicionamiento sobre el Derecho a la Sexualidad de las personas con discapacidad intelectual o del desarrollo. Plena Inclusión, Madrid (2021)

22. Di Giulio, G.: Sexuality and people living with physical or developmental disabilities: a review of key issues. Can. J. Hum. Sex 12(1), 53-68 (2003)

23. Freckelton, I.: Sexual surrogate partner therapy: legal and ethical issues. Psychiatry Psychol. Law 20(5), 643-659 (2013). https://doi.org/10.1080/13218719.2013.831725 
24. Martínez, O.I.: La figura del asistente sexual dentro del asistente personal:orígenes, marco legal en España e implantación de su figura en la sociedad. Universidad Internacional Menéndez Pelayo, Madrid (2016)

25. Centeno A. La asistencia sexual, recuperar nuestros cuerpos para recuperar nuestras vidas. En torno al debate sobre la asistencia sexual, desde la diversidad física (online). https://www.eldiario.es/ blogs/. (accessed 17/02/2020) Available at: https://www.eldiario.es/interferencias/asistencia-sexual-recuperar-cuerpos-vidas_132_1002837.html (2020)

26. Granja, H.F.: Protocolo de Acompañamiento Íntimo y Erótico (AIE) para personas con diversidad funcional, intelectual o mental, en especial para personas que están en situación de dependencia y tienen necesidades de apoyo extensas y generalizadas. Tandem Team, Barcelona (2018)

27. Bahner, J.: Sexual professionalism: for whom? The case of sexual facilitation in Swedish personal assistance services. Disabil. Soc. 30(5), 788-801 (2015). https://doi.org/10.1080/09687599.2015. 1021761

28. Kulick, D.: When privacy and secrecy collapse into one another, bad things can happen. Curr. Anthropol. 56(12), 241-250 (2015)

29. Lengyel, Z.M.: What describes the legal situation of disabled people in Denmark compared with the United States of America today with regards to their access to sexual services and their rights to live a meaningful erotic life? Copenhagen, (2019)

30. Garofalo Geymonat, G.: Disability rights meet sex workers' rights: the making of sexual assistance in europe. Sex Res. Soc. Policy (2019). https://doi.org/10.1007/s13178-019-0377-x

31. Agthe Diserens, C.: Au risque du désir. Reliance 29, 19-21 (2008). https://doi.org/10.3917/reli.029. 0019

32. Agthe Diserens, C.: La formation en assistance sexuelle : toute innovation implique des risques ! Reliance 29(3), 46-52 (2008). https://doi.org/10.3917/reli.029.0046

33. de Vries, N.: Le corps, même handicapé ou empêché, est un trésor. Reliance 29(3), 96-100 (2008)

34. Fumagali, L., Agthe Diserens, C.: Citoyen, homme, époux, père et assistant sexuel. Reliance 29(3), 22-25 (2008). https://doi.org/10.3917/reli.029.0022

35. Sánchez, E., Honrubia, M.: La asistencia sexual, una figura en construcción. Boletín Científico de ANSSYD 3, 34-49 (2017)

36. Kessler, S.: Mais qui sont-ils ? La sélection des candidats qui se destinent à l'assistance sexuelle. Reliance 29(3), 53-57 (2008). https://doi.org/10.3917/reli.029.0053

37. Soulier, B.: Accompagnement sexuel ou accompagnement sensuel ? Reliance 29(3), 107-112 (2008). https://doi.org/10.3917/reli.029.0107

38. Gammino, G.R., Faccio, E., Cipolletta, S.: Sexual assistance in Italy: an explorative study on the opinions of people with disabilities and would-be assistants. Sex Disabil. 34(2), 157-170 (2016). https://doi.org/10.1007/s11195-016-9435-y

39. Gutiérrez Bermejo, B., Jenaro, C.: Plan de sexualidad responsable para personas con discapacidad intelectual: El respeto hacia uno mismo y hacia los demás en las relaciones personales. Sanz y Torres, Madrid (2018)

40. Gutiérrez-Bermejo, B., Flores, N., Amor, P.J., Jenaro, C.: Evidences of an implemented training program in consensual and responsible sexual relations for people with intellectual disabilities. Int. J. Environ. Res. Public Health 18(5), 2323 (2021). https://doi.org/10.3390/ijerph18052323

41. Planche, F., Granget, P., Loew, F.: Implications de l'assistance sexuelle : regard éthico-légal. Reliance 29(3), 74-81 (2008). https://doi.org/10.3917/reli.029.0074

42. Gutiérrez Bermejo, B., Jenaro, C.: Plan de Prevención y Actuación ante el maltrato en los centros de atención a personas con discapacidad intelectual. Sanz y Torres, Madrid (2017)

43. Tassé, M.J., Wehmeyer, M.L.: Intensity of support needs in relation to co-occurring psychiatric disorders. Exceptionality 18(4), 182-192 (2010). https://doi.org/10.1080/09362835.2010.513922

44. Verdugo, M.-A., Arias, B., Ibáñez, A., Schalock, R.L.: Adaptation and psychometric properties of the Spanish version of the supports intensity scale (SIS). Am. J. Intellect. Dev. Disabil. 115(6), 496-503 (2010). https://doi.org/10.1352/1944-7558-115.6.496

45. Thompson, J.R., Bryant, B., Campbell, E.M., Craig, E.M., Hughes, C., Rotholz, D.A., Schalock, R.L., Silverman, W., Tasse, M., Wehmeyer, M.L.: Supports Intensity Scale; American Association on Intellectual and Developmental Disabilities. American Association on Mental Retardation, Washington, DC, USA (2004)

46. Jenaro, C., Cruz, M., del Carmen, M., Perez, N.E., Flores, V.V.: Utilization of the Supports Intensity Scale with psychiatric populations: psychometric properties and utility for service delivery planning. Arch. Psychiatr. Nurs. 25(5), e9-e17 (2011). https://doi.org/10.1016/j.apnu.2011.05.002 
47. Wehmeyer, M., Chapman, T.E., Little, T.D., Thompson, J.R., Schalock, R., Tassé, M.J.: Efficacy of the supports intensity scale (SIS) to predict extraordinary support needs. Am. J. Intellect. Dev. Disabil. 114(1), 3-14 (2009). https://doi.org/10.1352/2009.114:3-14

48. Murphy, G.H., O'Callaghan, A.: Capacity of adults with intellectual disabilities to consent to sexual relationships. Psychol. Med. 34(7), 1347-1357 (2004)

49. Schaafsma, D., Kok, G., Stoffelen, J.M.T., Curfs, L.M.G.: Identifying effective methods for teaching sex education to individuals with intellectual disabilities: a systematic review. J. Sex Res. 52(4), 412-432 (2015). https://doi.org/10.1080/00224499.2014.919373

50. Friedman, C.: Intimate relationships of people with disabilities. Inclusion (Wash) 7(1), 41-56 (2019). https://doi.org/10.1352/2326-6988-7.1.41

51. Friedman, C., Crabb, C.: Restraint, restrictive intervention, and seclusion of people with intellectual and developmental disabilities. Intellect. Dev. Disabil. 56(3), 171-187 (2018). https://doi.org/10.1352/ 1934-9556-56.3.171

52. Hamilton, C.A.: 'Now I'd like to sleep with Rachael'-researching sexuality support in a service agency group home. Disabil. Soc. 24(3), 303-315 (2009). https://doi.org/10.1080/096875909027894 61

53. Baines, S., Emerson, E., Robertson, J., Hatton, C.: Sexual activity and sexual health among young adults with and without mild/moderate intellectual disability. BMC Public Health 18(1), 667 (2018). https://doi.org/10.1186/s12889-018-5572-9

54. Gil-Llario, M.D., Morell-Mengual, V., Ballester-Arnal, R., Díaz-Rodríguez, I.: The experience of sexuality in adults with intellectual disability. J. Intellect. Disabil. Res. 62(1), 72-80 (2018). https://doi. org/10.1111/jir. 12455

55. Grove, L., Morrison-Beedy, D., Kirby, R., Hess, J.: The birds, bees, and special needs: making evidence-based sex education accessible for adolescents with intellectual disabilities. Sex Disabil. 36(4), 313-329 (2018). https://doi.org/10.1007/s11195-018-9547-7

56. Walters, F.P., Gray, S.H.: Addressing sexual and reproductive health in adolescents and young adults with intellectual and developmental disabilities. Curr. Opin. Pediatr. 30(4), 451-458 (2018). https:// doi.org/10.1097/MOP.0000000000000635

57. Chrastina, J., Večeřová, H.: Supporting sexuality in adults with intellectual disability—a short review. Sex Disabil. (2018). https://doi.org/10.1007/s11195-018-9546-8

Publisher's Note Springer Nature remains neutral with regard to jurisdictional claims in published maps and institutional affiliations. 